\title{
Performance Assessment of OSB Wood Composites with Added Wire Mesh
}

\author{
Amós Magalhães de Souza ${ }^{1}$, Fabiane Salles Ferro ${ }^{1}$, Felipe Hideyoshi Icimoto ${ }^{1}$, Diego Henrique Almeida ${ }^{2}$, \\ Marília da Silva Bertolini ${ }^{1}$, André Luis Christoforo ${ }^{3, *}$, Francisco Antonio Rocco Lahr ${ }^{4}$ \\ ${ }^{1}$ Department of Material Engineering, Engineering School of São Carlos (EESC/USP), São Carlos, 13566-590, Brazil \\ ${ }^{2}$ Pontifical Catholic University of Minas Gerais (PUC Minas), Department of Civil Engineering, Campus of Poços de Caldas, \\ Poços de Caldas, 37701-355, Brazil \\ ${ }^{3}$ Centre for Innovation and Technology in Composites - CITeC, Department of Civil Engineering (DECiv), Federal University of São \\ Carlos, São Carlos, 13565-905, Brazil \\ ${ }^{4}$ Department of Structural Engineering (SET), São Paulo University (EESC/USP), São Carlos, 13560-970, Brazil
}

\begin{abstract}
OSB panels were developed as a substitute for plywood. However, their properties in static bending, i.e. modulus of elasticity (MOE) and modulus of rupture (MOR) are often reduced. The aim of this study was to evaluate MOE and MOR of OSB manufactured with Pinus sp. and castor-oil based polyurethane resin, applying a wire mesh in order to improve those properties. Recommendations of normative document EN 310:1993 were obeyed. Results showed that mechanical properties considered are compatible with codes requirements and with values obtained by several authors in related literature. In static bending tests, the difference between parallel-to-grain MOE and MOR values of panels with and without wire mesh treatment was not significant. Statistical analysis reveals that the wire mesh pressing position does not affect MOE and MOR. However, these values are superior to those recommended, for OSB and plywood, by normative documents.
\end{abstract}

Keywords OSB, Polyurethane resin, Surface treated, Wire mesh

\section{Introduction}

Wood is a strong and renewable material, composed basically by fiber, polyoses and lignin. However, its physical, anatomical and chemical composition may vary among different species and within a single species. For that reason, dimensions, anisotropy and defects of a given tree constrain some of its applications [1].

Wood-based products have become an important alternative to solid wood in many applications, from structural elements and building components to furniture and packaging. Among these products are recomposed panels, which constitute an excellent substitute for sawn wood in many uses [2].

Among a number of types of panels produced by the wood-based industry, in structural applications OSB is deemed as the most important. This designed structural wood panel has become very popular in several applications due to its outstanding properties [3]. According to [4], OSB can be made of a wide range of rapid-growth and relatively small tree species, the manufacturing process has highly

* Corresponding author:

alchristoforo@yahoo.com.br (André Luis Christoforo)

Published online at http://journal.sapub.org/ijme

Copyright (C) 2014 Scientific \& Academic Publishing. All Rights Reserved automated and a high yield.

According to EN 300 [5], OSB is defined as a wood panel composed of multiple layers wood strands of predetermined shape, longer than $50 \mathrm{~mm}$ and thinner than $2 \mathrm{~mm}$, bound together by an adhesive. These strands are aligned parallel to the panel length in its outer layers, whereas, in its inner layer or layers, they can be randomly distributed or aligned perpendicular to those in the outer layers.

According to [6], in spite of physical properties of OSB being similar to those of plywood, their properties in static bending are generally inferior, thereby indicating that employing OSB instead of plywood should be preceded by in-depth investigation in light of the magnitude of properties required by the end use of products.

The purpose of this study was to manufacture and assess the performance of OSB manufactured with Pinus sp. strands and castor oil-based polyurethane resin, whose surfaces were reinforced with wire mesh. This wire mesh treatment aimed at increasing the mechanical properties in static bending of OSB.

\section{Material and Methods}

OSB boards were manufactured and tested at Wood and Timber Structures Laboratory (LaMEM), Structural Engineering Department (SET), São Carlos School of 
Engineering, University of São Paulo (EESC-USP), Brazil. OSB boards in this study were manufactured with strands of rejected wood pieces of Pinus sp with apparent density of $0.49 \mathrm{~g} / \mathrm{cm}^{3}$. According to [6], [7] and [8], the density of Pinus sp. is close to that required for use in the manufacture of OSB [9]. Castor oil-based polyurethane resin was used as a binding agent due to its outstanding performance in panels, as observed in previous studies such as [10], [11], [12] and [13].

Galvanized wire mesh was employed; its specifications are shown in Table 1. The use of a wire mesh was based on know-howfrom other fields that employ wire meshesas reinforcement (construction, soils), since research of this kind was is lacking with respect to wood-based panels. A 16-mesh wire mesh was used because it presented the best result in preliminary tests (bending).

In order to manufacture the composites, following equipment was used: circular saw (a); chipper (b); strand generator (c); oven (d); analytical balance (e); spray chamber (f); strand separator (g); mixer (h); digital caliper (i); heated hydraulic press (maximum load and temperature: 80 tons and $200^{\circ} \mathrm{C}$, respectively).

Parameters adopted in OSB manufacture were the same as those employed by [15]. Initially, rejected pieces Pinus sp. with moisture content near $12 \%$ was forwarded to carpentry, where they was sawn into $90 \mathrm{~mm}$ wide and $45 \mathrm{~mm}$ thick. These dimensions defined length and width of strands, which were generated by means of a disc chipper, whose knives had been adjusted to generate strands with thickness ranging from 0.40 to $0.90 \mathrm{~mm}$ (Figure 1).

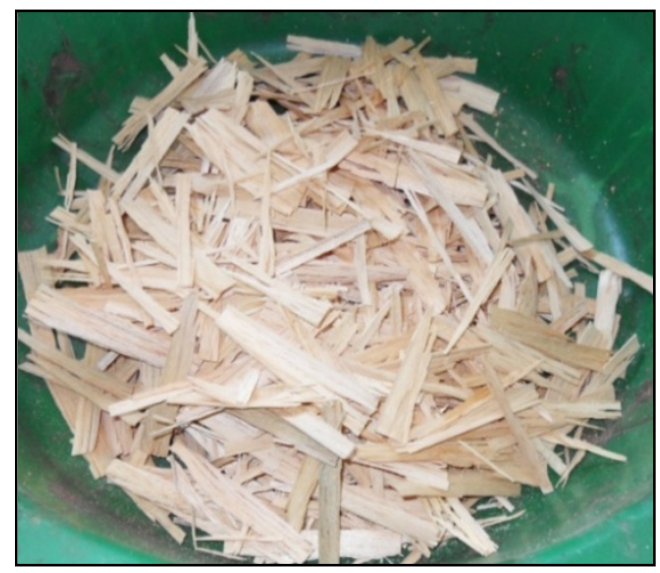

Figure 1. Wood particle (Strands)

The chipper-generated strands were weighed and placed in a spray chamber, in which the binding agent was sprayed with the aid of an air compressor and two pistols. First, polyol was applied, followed by the prepolymer [16] and [17]. Based on [13], the polyol/prepolymer weight ratio adopted was 1:1. In accordance with [10] and [11], resin content for all panels was $12 \%$, based on dry weight of strands. Adhesive-sprayed particles were placed in the separator (Figure 2).

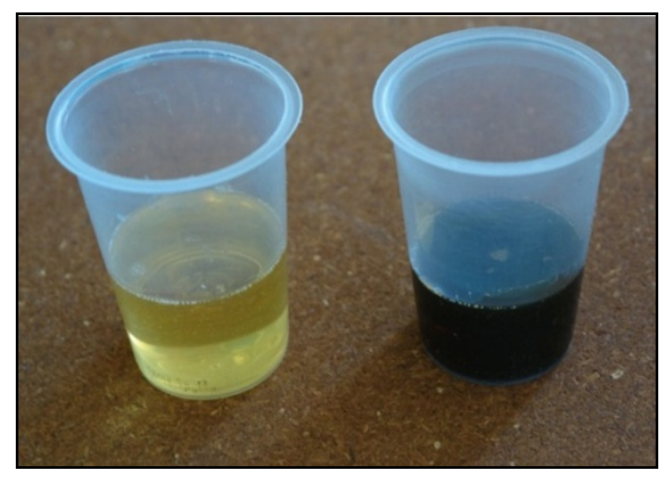

Figure 2. Polyol B1640 and prepolymer A249

Afterward, the strands were pre-pressed in order to improve the mattress conformation and prevent loss of strands. Subsequently, mattress was placed in a heated hydraulic press and subjected to a specific load of $4.5 \mathrm{MPa}$ for 10 minutes at $100^{\circ} \mathrm{C}$, as recommended by [15] and [11].

The wire mesh treatment was conducted during heated pressing process, in which the wire mesh was fixed onto the panel surface by means of load and temperature combined. Twelve panels were manufactured, four of which had the wire mesh pressed onto their top surfaces, four onto their bottom surfaces, and four onto neither of their surfaces (Figure 3).

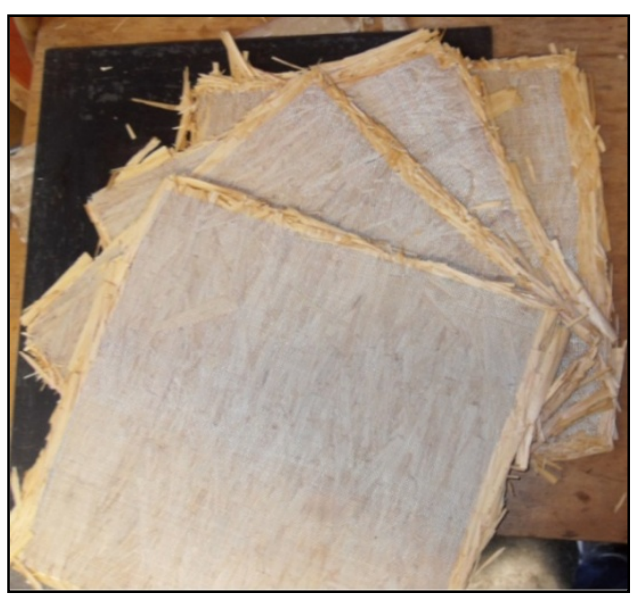

Figure 3. OSB with wire mesh

After manufacture, panels were cured for 72 hours to ensure good performance of the binding agent. Based on [8] and [18], it was adopted to emplace strands in the two outer layers and randomly distributed in the inner layer. In accordance with [8], the face/head/face ratio chosen was 20:60:20, based on the percentage of dry weight of adhesive-sprayed strands.

Table 1. Specifications of meshes used in the manufacture of panels. Source: Belgo [14]

\begin{tabular}{cccccc}
\hline Wiremesh $(\mathrm{mesh})$ & Wirediameter $(\mathrm{mm})$ & Opening the mesh $(\mathrm{mm})$ & \% Open area & Weight $\left(\mathrm{kg} / \mathrm{m}^{2}\right)$ & Strength $(\mathrm{MPa})$ \\
\hline 16 & 0,36 & 1,23 & 59,80 & 1,06 & $392-589$ \\
\hline
\end{tabular}


Static bending tests were performed as recommended by EN 310 [19]. Results obtained were statistically processed by analysis of variance (ANOVA) at 5\% level of significance. For validation of ANOVA, Anderson-Darling normality test, $\mathrm{F}$ and Levene's tests for homogeneity of variances [20] were employed. P-value greater than significance level implies accepting that treatments are not significant with respect to the properties under investigation, that responses have normal distribution and equivalence of variances.

\section{Results and Discussion}

The average parallel-to-grain modulus of elasticity (MOE) values of panels manufactured in this study and those of panels for special structural use in humid environment $(\mathrm{OSB} / 4)$ found in EN 300 [5] are shown in Figure 4.

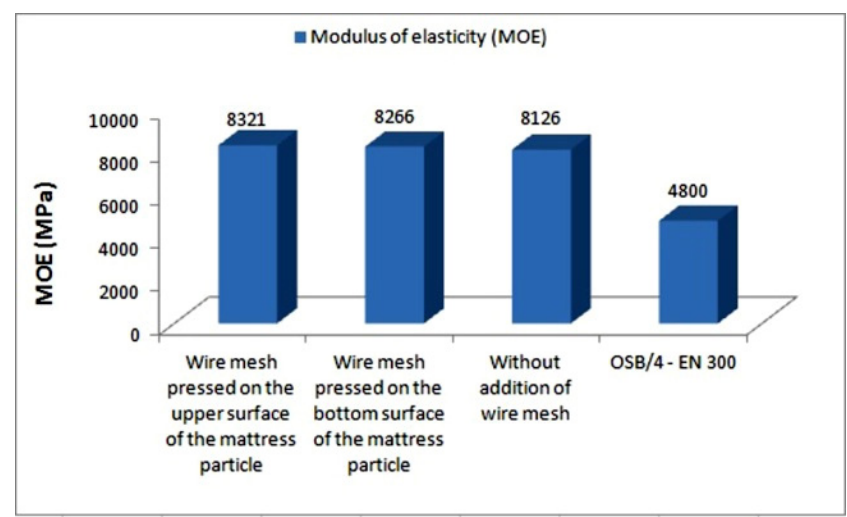

Figure 4. Parallel-to-grain modulus of elasticity (MPa)

It is possible to notice that $\mathrm{MOE}$ values for boards with and without wire mesh vary by $2 \%$ at most. Coefficients of variation $(\mathrm{Cv})$ varied between $4.6 \%$ and $16.7 \%$, which is in agreement with those obtained by [11] and [21]. This result may be attributed to the fact that strands ruptured first, which caused the entire tension load to be transferred to the wire mesh, thus causing its rupture.

The Figure 5 shows parallel-to-grain modulus of rupture (MOR) values for boards and compares them to those required by $\mathrm{OSB} / 4$ found in $\mathrm{EN} 300$ [5].

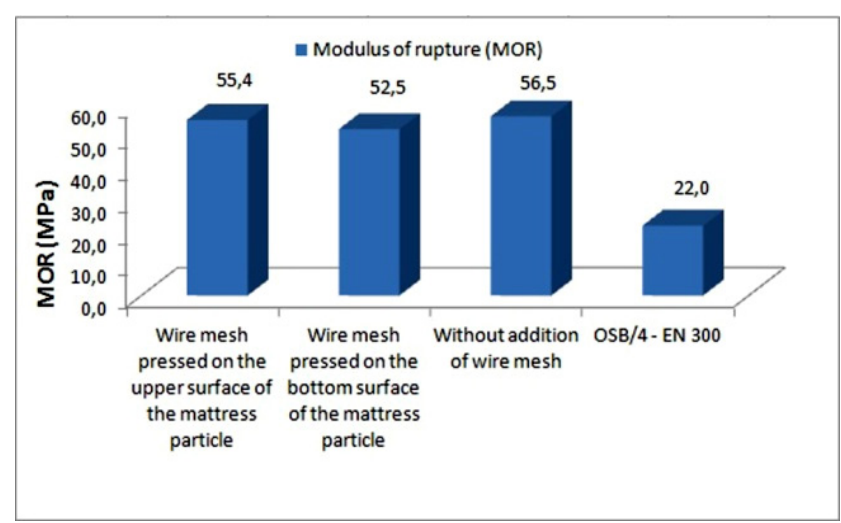

Figure 5. Parallel-to-grain modulus of rupture $(\mathrm{MPa})$
MOR values varied by $7 \%$ among panels at most (difference between the highest and lowest values) and $\mathrm{Cv}$ values ranged from $8.3 \%$ to $22.6 \%$.

The observed uniform distribution of points along the line meets the normality and homogeneity conditions required for validating ANOVA (P-value > 0.05). Results of Bartlett and Levene's test conducted to assess homogeneity among treatments, presented P-values ranging from 0.128 to 0.736 , which further validates ANOVA.

In ANOVA, experimental MOE values ranged from 5,846 MPa to $11,819 \mathrm{MPa}$. P-value of 0.838 indicated that the wire mesh position was not significant with regard to MOE. Experimental MOR values ranged from 32.3 MPa to 74.7 MPa. P-value 0.304 indicated that the pressing position did not influence MOR.

It worthy of note that, compared to normative documents regarding $\mathrm{OSB} / 4$ in $\mathrm{EN} 300$ [5] and plywood for reinforced concrete molds in DIN 68792[22], MOE values were at least $40 \%$ and $39 \%$ higher, respectively. When compared to MOR values required for OSB/4 in EN 300[5], plywood employed in building construction in DIN 68705-3[23], and five-layered plywood in DIN 68792[22], the values obtained in this study are at least $58 \%, 24 \%$, and $14 \%$ higher, respectively. The average parallel-to-grain modulus of elasticity (MOE) and modulus of rupture (MOR) results was similar to those found by [24].

\section{Conclusions}

Based on the methodology employed and results obtained for OSB treated with wire mesh, it is possible to conclude that:

In static bending tests, the difference between parallel-to-grain MOE and MOR values of panels with and without wire mesh treatment was not significant. Statistical analysis reveals that the wire mesh pressing position does not affect MOE and MOR. However, these values are superior to those recommended, for OSB and plywood, by normative documents.

In light of the above results, it may be affirmed that although the manufacture of OSB with wire mesh, Pinus sp. wood strands and castor oil-based polyurethane resin isn't viable. The use of wire meshes become sun necessary because the additions of MOE and MOR were irrelevant. However, OSB without wire mesh showed excellent results when compared to the values required by the regulations cited.

\section{ACKNOWLEDGEMENTS}

The authors gratefully acknowledge the financial support provided by Fundação para o Amparo à Pesquisa do Estado de São Paulo - FAPESP (Proc: 2012/14352-3) and the Coordenação de Aperfeiçoamen to de Pessoal de Nível Superior - CAPES. 


\section{REFERENCES}

[1] P. Feraboli Notched response of OSB wood composites. Compos Part A - ApplSci, 39, 1355-1361, 2008.

[2] M. S. Bertolini.; F. A. Rocco Lahr.; M. F. Nascimento.; J. A. Agnelli. Accelerated artificial aging of particleboards from residues of CCB treated Pinus sp. and castor oil resin. Materials Research, 16, 293-303, 2013.

[3] EPF. O painel derivado de madeira mais versátil dos nossos dias. Available in: $<$ http://www.europanels.org $>$. Access in 08 aug 2013.

[4] APA. Oriented Strand Board (OSB). Available in: .<http://www.apawood.org>. Access in 08 jun 2013.

[5] European Standard. EN 300: Definitions, classification and specifications. Portugal. 2006.

[6] G. BortolettoJúnior.; J. N. Garcia. Propriedades de resistência e rigidez à flexão estática de painéis OSB e compensados. Materials Research, 28(4), 563-570, 2004.

[7] L. M. Mendes, S. Iwakiri, J. L. M. Matos, S. Keinert JR, L. K.Saldanha Efeitos da densidade, composição dos painéis e teor de resina nas propriedades de painéis OSB. Floresta e Ambiente, 10, 57- 67, 2003.

[8] S. Iwakiri, L. M. Mendes, L. K. Saldanha Produção de chapas de partículas orientadas "OSB" de Eucalyptus grandis com diferentes teores de resina, parafina e composição em camadas Ciência Florestal, 13, 89-94, 2002.

[9] A. M.Souza. Productionand performance evaluation of Pinus sp oriented strandboard (OSB) with metallic gauze inclusion. Ms thesis. São Carlos: University of São Paulo, 2012.

[10] F. M.Dias.; F. A. R. Lahr. Alternative Castor-Oil Based Polyurethane Adhesive Used in the Production of Plywood Materials Research, 7(3), pp. 413-420, 2004.

[11] M. F. Nascimento.; E. A. M. Morales.; F. A. R. Lahr.; A. L. Christoforo; A. Carvalho. Chapas de OSB com Uso de Madeiras Nativas. Revista da Madeira, 1, 1- 4, 2011.

[12] F. S.Ferro. Painéis OSB com madeira Schizolobium amazonicum e resina poliuretana à base de óleo demamona: viabilidade técnica de produção. Ms thesis. São Carlos:
University of São Paulo, 2012.

[13] M. S. Bertolini.; M. F. Nascimento.; K. A. Blecha.; F. A. Rocco Lahr. Eco-panels Based on Wastes from Urban Trees and Castor Oil Polyurethane Resin. International Journal of Agriculture and Forestry, 3, 12-15, 2013.

[14] Belgo. Aramegalvanizadocomercial. Available in: < http://www. belgobekaert.com.br>. Access in 08 jun 2013.

[15] L. M. Mendes et al. Influência da densidade do painel e da composição em camadas nas propriedades físico-mecânicas de painéis OSB de clones de Eucalyptus spp. Cerne, 14, 379-385, 2008.

[16] A. J. P. Silva; F. A. L. Rocco; A. L. Christoforo; T. H. Panzera. Properties of Sugar Cane Bagasse to use in OSB International Journal of Composite Materials, 2, 50-56, 2013.

[17] S. A. M. Silva.; A. L. Christoforo.; S. L. M. Ribeiro Filho.; L. D. Varanda; F. A. L. Rocco. Particleboard Manufactured with Bicomponent Polyurethane Resin base on Castor Oil International Journal of Composite Material, 2, 115-118, 2012.

[18] A. Cloutier. Oriented strandboard (OSB): raw material, manufacturing process, properties of wood-base fiber and particle materials. In: international seminar on solid wood products of high technology, 1, 173-185, 1998.

[19] European Standard. EN 310: Determination of modulus of elasticity in bending and of bending strength, Bruxelas. 1993.

[20] D. C. Montgomery Design and analysis of experiments. Arizona: John WIley@ Sons Inc., 2005.

[21] M. F. Nascimento.; F. A. Rocco Lahr.; A. L.Christoforo. Painéis tipo OSB fabricados com madeiras brasileiras: produção e avaliação de desempenho. In: CIMAD 11 Congresso Ibero-Latino Americano da Madeira na Construção, Portugal, Universidade de Coimbra, 2011.

[22] Deutsches Institutfür Normung. DIN 68792: Large area shuttering panels of veneer plywood for concrete and reinforced concrete. 1979.

[23] Deutsches Institutfür Normung. DIN 68705-3: Plywood: building-veneer plywood. 1981.

[24] L. M. Mendes.; S. Iwakiri.; J. L. M. Matos.; S. Keinert. JR, L. K.Saldanha. Pinus spp. na produção de painéis de partículas orientadas (OSB). Ciências Florestal, Santa Maria, 12(2), 135-14, 2002. 